\title{
A survey on decentralized steel industries
}

\author{
Mostafa Jafari ${ }^{\mathrm{a}^{*}}$ and Naser Heidari ${ }^{\mathrm{a}}$
}

${ }^{a}$ Department of Industrial Engineering, Iran University of Science and Technology, Narmak, Tehran Iran

\section{A R T I C L E I N F O}

Article history:

Received 1 June 2010

Received in revised form

10 September 2010

Accepted 14 September 2010

Available online

14 September 2010

Keywords:

Steel Industry

Small-scale Steel

Mini-Mill

Productivity

Decentralization

\begin{abstract}
A B S T R A C T
During the past three decades there have been tremendous efforts on building steel factories on economic scales. The primary question is to find an economic scale for such plants which could also meet domestic demand. In this paper, we perform an empirical survey to find out whether building small steel factories are more suitable or setting up giant steel industries to meet regional demands. The results indicate that in many countries, building small steel plants based on the recent advances of technologies not only reduces the total cost of steel production but also it could significantly reduce the unnecessary transportation cost, providing cheaper labor, etc. This would lead to better competition which would increase the productivity.
\end{abstract}

C 2010 Growing Science Ltd. All rights reserved.

\section{Introduction}

The new millennium started with many incidents in the world which hurt the growth on global economics. From the infamous incident of September, 11, 2001 to turmoil in global market started from real-state in US economy. we learned that the global market did not create good environment for metal industries in many events. During the past few years, there have been different cycles on steel price and many steel plants were faced with crises when the cost of steel was relatively higher than the selling price. The supply chain management of big steel producers normally requires them to place their orders for raw materials four to six months in advance. This lag in a bear market could create significant troubles for steel producers since the price of steel could drop, significantly. This bullwhip effect often hurts big steel producers much more than small mini mill producers (Wu, D-Y., \& Katok, 2006).

The other issue on comparing large-scale industries with mini mill is the time that a new plant could start its production (Johansson \& Holappa, 2004). It normally takes, at least, three to five years for a regular steel plant to reach its production stage where as this period could take between one to two years for mini mill plants. Astier (1998) is believed to be the first person who surveyed the impact of 
mini-mills on US economy and offered suggestions on implementing mini-mills on other industries. A short period of plant commissioning has many advantages. First, we may take advantage of the new advances on technology. Second, the return on investment is faster which is more favorable among short term investors. The other issue with megaplants steel industries is the massive layoff they need in order to cope with economic crises. The big layoff in steel industries in such events may create more social and governmental problems especially in the event that the industry has not been privatized yet. Normally, a typical governmental giant steel unit works with almost no layoff in economic turmoil adding more loss on its statement in an attempt to minimize the growth on unemployment which means lower productivity (Ray \& Kim, 1995). However, a small-cap steel unit could reduce its forkforse very easily. The primary focus on most of the mini-mills is to use steel scrap in steel production and there has been an increase on using steel scrap to produce good quality irons. There are several reasons to build mini-mills to produce steel: First, it helps us recycle the scrap steel and move towards having better environment. Second, this type of steel production could save us energy consumption by over 50\%. Third, the steel industry needs much less investment which makes it tractable for small cap business investors (Lieberman, \& Johnson, 1999). In this paper, we perform a survey on the advantages of using the mini-mills versus giant steel industries. The empirical analysis is performed based on a questioner including various questions. The results are validated and suggestions are derived to guide eager investors in small-cap steel plants. This paper is organized as follows. We first present the details of the proposed survey in section 2 . In section 3 , the implementation of our survey and statistical analysis are performed. The concluding remarks are given at the end to summarize the contribution of this paper.

\section{Proposed Method}

During the past two decades, there have been various evidences on developing decentralized steel plants. The so called mini-mills have been widely used in United States and many other developed countries. However, one may argue whether we can generalize the idea of having small units of steel plants on any developing countries. In fact, we may make a statement on using such small plants only when this kind of business is successfully used in almost all developing countries. Although there are many advantages on using this kind of plants, we may not rely solely on the experience of some developed countries to make a strategic decision for developing countries. In this study, we design a survey which includes 24 questions. These questions are mainly focused on decentralization of steel industry and they are categorized in seven groups which are summarized in Table 1.

Table 1

The descriptions of seven groups of questions

\begin{tabular}{|c|c|c|}
\hline Item & Question \# & Description \\
\hline 1 & $1,9,17$ & Decentralized steel industry could reduce the plant commissioning. \\
\hline 2 & $2,10,18$ & $\begin{array}{l}\text { Decentralized steel industry could reduce the total investment needed } \\
\text { for this sector. }\end{array}$ \\
\hline 3 & $3,11,19$ & Decentralized steel industry could reduce the term return on capital. \\
\hline 4 & $4,12,20$ & $\begin{array}{l}\text { Decentralized steel industry could reduce the transportation cost and } \\
\text { speed up the sales of products. }\end{array}$ \\
\hline 5 & $5,13,21$ & $\begin{array}{l}\text { Decentralized steel industry could create job opportunity in different } \\
\text { parts of the countries with lower labor market. }\end{array}$ \\
\hline 6 & $6,14,22$ & Decentralized steel industry could reduce the setup times. \\
\hline 7 & $7,15,23$ & $\begin{array}{l}\text { Decentralized steel industry could facilitate the preventive } \\
\text { maintenance. }\end{array}$ \\
\hline 8 & $8,16,24$ & The Summary \\
\hline
\end{tabular}

As we can observe from Table 1, we repeat every question three times in order to make sure that the replies are gathered, rationally. The next step in our survey is to calculate the sample size of our 
survey. In this survey, we decided to do the survey among all specialists in steel industry. The population of our survey covers 2600 people and the maximum error in our computation does not have to exceed five percent. The questions are in qualitative perspective from very low to very high in Likert scale (Likert, 1932) and we divid them into two groups by merging the first two items of very low and low into one group and the other three items of average, high and very high are located into other group. We also assigned weight values of one to five for different scales from very low to very high, respectively. Therefore, all questions are divided into two groups of binary classifications, i.e. yes/no. Finally we assume the population follows a normal distribution. Therefore we could use the following formula to calculate the minimum number of sample size,

$n=\frac{N \times z_{\alpha / 2}^{2} \times p \times q}{\varepsilon^{2} \times(N-1)+z_{\alpha / 2}^{2} \times p \times q}$,

where $N$ is the population size, $p=1-q$ represents the yes/no categories, $z_{\alpha / 2}$ is CDF of normal distribution and finally $\varepsilon$ is the error term. Since we have $p=0.5, z_{\alpha / 2}=1.96$ and $N=2600$, the number of sample size is calculated as $n=255$. Table 2 shows the educational levels of the people who participated in our survey.

Table 2

The educational level of the sample size

\begin{tabular}{llll}
\hline Years of University education & Frequency & Percentage & Cumulative percentage \\
\hline No response & 4 & 1.57 & 1.57 \\
2 & 91 & 35.69 & 37.25 \\
4 & 16 & 6.27 & 43.53 \\
6 & 127 & 49.80 & 93.33 \\
10 & 17 & 6.67 & 100 \\
\hline Total & 255 & 100 & \\
\hline
\end{tabular}

As we can observe from Table 2, the people who took part in our survey have good educational background from different fields with good experience on steel industry. The next step is to measure the reliability of our survey using the following,

$R=\left(\frac{J}{J-1}\right)\left(1-\frac{\sum S_{i}^{2}}{S^{2}}\right)$

where $J$ is the number of subset questions, $S_{i}^{2}$ is the variance of the sub-hypothesis and $S^{2}$ is the variance of whole hypothesis and finally $R$ is the Cronbach alpha (Cronbach, 1951) which indicates the reliability of the test. Note that $R$ is limited between zero and one and a desirable value close to one validates the test. The overall $R$ for our survey is calculated as 0.7725 which means that the results are reliable. One of the most important questions on our survey was that decentralizing steel industry could lead to better utilization of resources. It could also increase the productivity of steel plants and it could reduce the total expenditure needed for developing countries. The survey confirms this question with $R=0.7725$.

\section{Results and Discussion}

In this section we analyze the details of the survey on seven different questions of this research given in Table 1. The data for all 255 survey results are gathered using Microsoft Excel software package and the statistical tests are performed using a specialized software packages called SPSS. 


\subsection{The impact of short setup and construction}

One of the questions is to look for the effects of a fast setup in decentralized steel facilities as a competitive advantage of this kind of units. A binomial test (Siegel, 1956) is used to verify this hypothesis with the following hypothesis,

$\left\{\begin{array}{l}\text { Ho: A short period of construction has no effects on decentralized steel units }(p<0.50) . \\ \text { H1: A short period of construction has effects on decentralized steel units }(p \geq 0.50) .\end{array}\right.$

Table 3 summarizes the results of our survey for this hypothesis. As we can observe from Table 3, the null hypothesis $(p<0.50)$ would be rejected with the likelihood of 92.68. In other words, we do not have enough evidence to accept that a fast construction and setting up a new plant have no effects on decentralized steel units.

Table 3

The summary of the survey on the impact of short period of construction of small units

\begin{tabular}{llllll}
\hline Group & Part & \# of samples & Probability & The likelihood & Sig. \\
\hline 1 & $p<0.50$ & 56 & 7.32 & & \\
2 & $p \geq 0.50$ & 709 & 92.68 & 0.50 & 0.000 \\
\cline { 1 - 2 } Total & 765 & 100 & & \\
\hline
\end{tabular}

\subsection{The impact of small investment needed to run a small-cap steel industry}

The other question of our survey is to measure the impact of small investment on small-cap steel plants. A binomial test is used to verify this hypothesis with the following hypothesis,

$\left\{\begin{array}{l}\text { Ho: A small investment has no effects on decentralized steel units }(p<0.50) . \\ \text { H1: A small investment has effects on decentralized steel units }(p \geq 0.50) .\end{array}\right.$

Table 4 summarizes the results of our survey for this hypothesis.

Table 4

The summary of the survey on studying the impact of small investment on steel units

\begin{tabular}{llllll}
\hline Group & Part & \# of samples & Probability & The likelihood & Sig. \\
\hline 1 & $p<0.50$ & 50 & 6.54 & & \\
2 & $p \geq 0.50$ & 715 & 93.46 & 0.50 & 0.000 \\
\cline { 1 - 3 } Total & 765 & 100 & & \\
\hline
\end{tabular}

Again, Table 4 confirms that we do not have evidence to say that small investment has no significant impact on small steel units. Therefore with the likelihood of 93.46 percent we could claim that small investment is a good reason on choosing small cap steel industries. 


\subsection{The impact of short term return on capital}

Another question in our survey is to study the impact of short term return on capital as an advantage on small-cap steel plants. A binomial test is used to verify this hypothesis with the following hypothesis,

$\left\{\begin{array}{l}\text { Ho: A short term return on capital has no effects on decentralized steel units }(p<0.50) . \\ \text { H1: A short term return on capital has effects on decentralized steel units ( } p \geq 0.50) .\end{array}\right.$

Table 5 summarizes the results of our survey for this hypothesis.

Table 5

The summary of the survey on the impact of short term return on capital on steel units

\begin{tabular}{llllll}
\hline Group & Part & \# of samples & Probability & The likelihood & Sig. \\
\hline 1 & $p<0.50$ & 63 & 8.24 & & \\
2 & $p \geq 0.50$ & 702 & 91.76 & 0.50 & 0.000 \\
\cline { 1 - 2 } Total & 765 & 100 & & \\
\hline
\end{tabular}

The result of Table 5 also confirms that we cannot claim a short term return on capital has no effect on small-cap steel industry.

\subsection{The impact of low transportation cost}

One more question in our survey is to consider the impact of low transportation cost as an advantage on small-cap steel plants with the following hypothesis,

$\left\{\begin{array}{l}\text { Ho: A low cost transportation has no effects on decentralized steel units }(p<0.50) . \\ \text { H1: A low cost transportation has effects on decentralized steel units }(p \geq 0.50) .\end{array}\right.$

Table 6 summarizes the results of our study for this hypothesis.

Table 6

The summary of the survey on the impact of low transportation cost on steel units

\begin{tabular}{llllll}
\hline Group & Part & \# of samples & Probability & The likelihood & Sig. \\
\hline 1 & $p<0.50$ & 127 & 16.60 & & \\
2 & $p \geq 0.50$ & 638 & 83.40 & 0.50 & 0.000 \\
\cline { 1 - 3 } Total & 765 & 100 & & \\
\hline
\end{tabular}

The result of Table 6 also confirms that we cannot claim a low transportation cost has no effect on small-cap steel industry. 


\subsection{The impact of cheap labor market}

The other question in our survey is to study the impact of cheap labor market as an advantage on small-cap steel plants.

$\left\{\begin{array}{l}\text { Ho: A low labor market has no effects on decentralized steel units }(p<0.50) . \\ \text { H1: A low labor market has effects on decentralized steel units }(p \geq 0.50) .\end{array}\right.$

Table 7 summarizes the results of our study for this hypothesis.

Table 7

The summary of the survey on the impact of low labor market on steel units

\begin{tabular}{llllll}
\hline Group & Part & \# of samples & Probability & The likelihood & Sig. \\
\hline 1 & $p<0.50$ & 112 & 14.64 & & \\
2 & $p \geq 0.50$ & 653 & 85.36 & 0.50 & 0.000 \\
\cline { 1 - 3 } Total & 765 & 100 & & \\
\hline
\end{tabular}

Table 7 is another evidence to for small-cap steel industries. The results indicate that there is more than 85 percent chance that small-cap steel has significant effect on our decision to prefer this kind of industry to big cap steel business.

\subsection{The impact of fast setup}

One more question in our research is to see the impact of a fast setup as an advantage on small-cap steel plants.

$\left\{\begin{array}{l}\text { Ho: A fast setup has no effects on decentralized steel units }(p<0.50) . \\ \text { H1: A fast setup has effects on decentralized steel units }(p \geq 0.50) .\end{array}\right.$

Table 8 summarizes the results of our study for this hypothesis.

Table 8

The summary of the study on the impact of fast setup on steel units

\begin{tabular}{llllll}
\hline Group & Part & \# of samples & Probability & The likelihood & Sig. \\
\hline 1 & $p<0.50$ & 183 & 23.92 & & \\
2 & $p \geq 0.50$ & 582 & 76.08 & 0.50 & 0.000 \\
\cline { 1 - 3 } Total & 765 & 100 & & \\
\hline
\end{tabular}

The results of Table 8 also confirm that setup is an advantage to use small-cap steel industries. However, when we compare our data with the results of Table 3 to Table 7, the results of this part is not as important as the previous questions for choosing small-cap steel versus big cap steel business. 


\subsection{The impact of low maintenance cost}

One more advantage of small-cap steel industry is the ease of maintenance on this kind plant. We examined the impact of this feature as a competitive advantage and the results are given in Table 9.

Table 9

The summary of the study on the impact of easy maintenance on steel units

\begin{tabular}{llllll}
\hline Group & Part & \# of samples & Probability & The likelihood & Sig. \\
\hline 1 & $p<0.50$ & 230 & 30.07 & & \\
2 & $p \geq 0.50$ & 535 & 69.93 & 0.50 & 0.000 \\
\cline { 1 - 3 } Total & 765 & 100 & & \\
\hline
\end{tabular}

As we can observe, the results confirm that easy maintenance could be an advantage on this kind of business but it is not as important as the issues discussed earlier.

\subsection{The impact of decentralization of steel industry on all seven factors}

In summary, we perform an additional test to study the effects of the all seven discussed issues on decentralized steel industry and the results are summarized on Table 10.

Table 10

The summary of the study on the impact of all seven factors on steel units

\begin{tabular}{llllll}
\hline Group & Part & \# of samples & Probability & The likelihood & Sig. \\
\hline 1 & $p<0.50$ & 106 & 13.86 & & \\
2 & $p \geq 0.50$ & 659 & 86.14 & 0.50 & 0.000 \\
\cline { 1 - 2 } Total & 765 & 100 & & \\
\hline
\end{tabular}

As we can observe, the results of Table 10 strongly reject the null hypothesis that the seven factors have no impact on choosing small-cap steel industries.

\subsection{The impact of decentralization on productivity}

Finally, we may wish to see whether the implementation of a small-cap steel industry through decentralization could lead us to have plants with higher productivity, lower expenses and better utilization of resources. This question was examined through a hypothesis similar to what we explained previously and the results are summarized in Table 11.

Table 11

The summary on the impact of small-cap steel unit on lowering the expenses and increasing the productivity

\begin{tabular}{llllll}
\hline Group & Part & \# of samples & Probability & The likelihood & Sig. \\
\hline 1 & $p<0.50$ & 927 & 15.15 & & \\
2 & $p \geq 0.50$ & 5193 & 84.85 & 0.50 & 0.000 \\
\cline { 1 - 3 } Total & 6120 & 100 & & \\
\hline
\end{tabular}


According to our survey, most people believe that small-cap steel industries could significantly reduce the cost of steel industry, increase the productivity by better utilization of resources.

\section{Conclusion}

In this paper, we have studied the impact of small-cap steel industry for developing countries. The results of this survey have indicated that this kind of business could significantly help us increase the productivity on steel industry. The setup and the construction of small-scale steel industry is much less than the traditional giant ones and this could help many countries develop faster. It needs smaller investment and short term return on capital which could reduce the risk of investment. Many developing countries have cheap labor market in different regions which is another advantages of decentralized steel industry. It also reduces the cost of transportation which is becoming a more important issue as the energy prices are on the rise.

\section{Acknowledgment}

The authors would like to thank the annonymous referees for their constructive comments on earleir version of this paper.

\section{References}

Astier J. (1998).The impact of mini-mills in the USA. Ironmaking and Steelmaking, 25(1),7-12.

Cronbach, L. J. (1951). Coefficient alpha and the internal structure of tests. Psychometrika, 16(3), 297-334.

Johansson, A., \& Holappa, L. (2004). From megaplants to mini-mills:a trend in steelmaking, a prospect for papermaking. Conservation and Recycling, 40(2), 173-183.

Likert, R. (1932). A Technique for the Measurement of Attitudes. Archives of Psychology, 140, 1-55.

Lieberman, M. B. \& Johnson, D. R. (1999). Comparative productivity of Japanese and U.S. steel producers, 1958-1993, Japan and the World Economy, 11(1), Pages 1-27.

Wu, D-Y., \& Katok, E. (2006). Learning, communication, and the bullwhip effect, Journal of Operations Management, 24(6), 839-850.

Ray, S. C. \& Kim, H. J. (1995). Cost efficiency in the US steel industry: A nonparametric analysis using data envelopment analysis , European Journal of Operational Research, 80(3), 654-671.

Siegel, S. (1956). Nonparametric statistics for the behavioral sciences. NY: McGraw-Hill. 